\title{
INTERIORIZACIÓN DE LOS FALSOS MITOS DEL AMOR ROMÁNTICO EN JOVENES
}

\section{INTERNALITATION OF FAKE MYTHS RELATED TO THE ROMANTIC LOVE AMONG YOUNG PEOPLE}

\author{
Marroquí, M.; Cervera, P. Universidad de Granada \\ Supervisado por: José Miguel García Ramírez. Departamento de Psicología Social. Universidad de Granada \\ Fecha de recepción: 30 de abril de 2014. \\ Fecha de revisión: 5 de mayo de 2014. \\ Fecha de aceptación: 12 de mayo de 2014.
}

Resumen: Este estudio se ha realizado para conocer y evaluar la interiorización de los falsos mitos del amor romántico en jóvenes de edades comprendidas entre 18 y 35 años, y el peligro que esta interiorización puede conllevar a la hora de establecer y soportar relaciones de pareja dañinas. Para ello, hemos utilizado la escala de mitos sobre el amor (Bosch et al. 2007), en una muestra de 153 jóvenes. Los datos obtenidos han mostrado que algunos falsos mitos que muestran una tendencia claramente sexista o con connotaciones de violencia como "se puede amar a alguien a quien se maltrata", "se puede maltratar a alguien a quien se ama" o "los celos son una muestra de amor", reciben un rechazo casi absoluto, alrededor del $90 \%$. Mitos que muestran un prejuicio más sutil como "el amor lo puede todo" o "solo existe una media naranja para mí", y "el amor es ciego" está muy interiorizado entre los jóvenes, alrededor de un $73 \%$ opinan que el amor lo puede todo y un $65 \%$ de los encuestados que solo existe una media naranja para ellos y un $70,6 \%$ que el amor es ciego. Pretendemos relacionar esta interiorización de los mitos generalizados en nuestra sociedad, con el sexismo existe y el machismo benevolente que está proliferando actualmente, ya que en la mayoría de estos supuestos la mujer tiene un carácter de inferioridad y sumisión. El peligro de estas creencias es aceptar actitudes y comportamientos en la pareja dañinos que puedan desembocar en violencia de género.

Palabras clave: prejuicio, violencia doméstica, joven.

\section{Introducción}

Un mito es una creencia, aunque se halla formulada de manera que aparece como una verdad y es expresada de forma absoluta y poco flexible. Estas creencias suelen poseer una gran carga emotiva, concentran muchos sentimientos, y suelen contribuir a crear y mantener la ideología del grupo y, por ello, suelen ser resistentes al cambio y al razonamiento lógico (Bosch y Ferrer, 2002).

El amor romántico, como construcción social del amor y de la familia, surge en Europa a principios del S.XIX, definiendo los roles que cada persona debe de tener en el ámbito familiar, dando unas pautas estáticas de lo que es el verdadero amor, que tiene 
como finalidad la entrega total a la otra persona, que esta sea lo único y fundamental en tu existencia.

Algunas de las características principales del concepto de amor romántico son los siguientes (Bosch, E. 2007):

- Vivir experiencias muy intensas de felicidad o de sufrimiento.

- Depender de la otra persona y adaptarse a ella, postergando lo propio.

- Perdonar y justificar todo en nombre del amor.

- Estar todo el tiempo con la otra persona.

- Pensar que es imposible volver a amar con esa intensidad.

- Desesperar ante la sola idea de que la persona amada se vaya.

- Prestar atención y vigilar cualquier señal de altibajos en el interés o el amor de la otra persona.

- Idealizar a la otra persona no aceptando que pueda tener algún defecto.

- Sentir que cualquier sacrificio es positivo si se hace por amor a la otra persona.

- Hacer todo junto a la otra persona, compartirlo todo, tener los mismos gustos y apetencias.

De estas características surgen los falsos mitos del amor romántico que aun en la actualidad persisten arraigados en nuestra sociedad.

Los falsos mitos que hemos utilizado para realizar nuestra investigación son los siguientes:

- La media naranja: en alguna parte hay alguien predestinado para cada persona.

- La pasión intensa de los primeros tiempos de una relación debería durar para siempre.

- El amor es ciego.

- El matrimonio es la tumba del amor.

- Se puede ser feliz sin tener una relación de pareja.

- Los celos son una prueba de amor.

- Separarse o divorciarse es un fracaso.

- Se puede amar a alguien a quien se maltrata.

- Se puede maltratar a alguien a quien se ama.

- El amor verdadero lo puede todo.

La mayoría de estos mitos, relegan a las mujeres a un plano secundario, en que él hombre tiene el deber de protegerla y/o someterla. Estas creencias también otorgan a la mujer características como la paciencia, la dulzura, la comprensión y el rol de cuidadora en la familia, a la vez que al hombre se le otorga el deber de proteger y mantener a la familia, la agresividad, la valentía y la valía en el trabajo.

Estos prejuicios son los predominantes actualmente en nuestra sociedad, y aunque son sutiles e prácticamente imperceptibles al haber interiorizado durante siglos estos principios, son muy peligrosos, dando lugar al machismo benévolo, que actualmente se encuentra en nuestra sociedad, y propiciando el caldo de cultivo perfecto para que la violencia de género siga alcanzando cotas históricas cada año.

Esta investigación se ha realizado entre población joven, debido a que se han multiplicado los casos de violencia de género entre este colectivo. Aunque se ha criado en una sociedad aparentemente democrática, con igualdad de derechos, sigue 
proliferando la violencia de género y el desequilibrio de poder entre hombres y mujeres.

Queremos observar si existe relación entre la interiorización de determinados mitos del amor romántico, y el normalizar los principales indicios de una relación con violencia de género, haciendo que la mujer no sea consciente hasta que no está totalmente sometida y le es muy difícil romper esa relación.

Pretendemos, mostrar que los valores que se esconden detrás de estos mitos que se trasmiten durante generaciones, integran actitudes sexistas y un ideal de relación de pareja equivocado, despertando una actitud más crítica al respecto y evitar normalizar actitudes machistas en una relación de pareja inadmisibles en una sociedad igualitaria.

\section{Método}

Objetivo General: Comprobar la interiorización de los falsos mitos del amor romántico en la población juvenil comprendida entre los 18 y 35 años.

Objetivos específicos: 1. Medir el prejuicio sutil de carácter sexista existente entre los jóvenes. 2. Analizar la correlación entre la interiorización de los falsos mitos del amor romántico entre los jóvenes y la posibilidad de tolerar comportamientos machistas en sus relaciones personales.

\section{Participantes}

Este estudio se ha realizado con una muestra de 153 jóvenes (39 hombres y 117 mujeres) de edades comprendidas entre los 18 y 35 años, de distintas comunidades autónomas.

\section{Instrumento}

Los participantes han completado la escala sobre los falsos mitos del amor romántico (Bosch et al., 2007) compuesto por 10 preguntas, describiendo los falsos mitos del amor romántico más extendidos socialmente.

La escala de respuestas es tipo Likert de 5 opciones; 1 - completamente desacuerdo; 2- en desacuerdo; 3- neutral (ni de acuerdo ni desacuerdo; 4- de acuerdo; 5completamente de acuerdo.

Para evaluarlo hemos utilizado el programa SPSS, el cual nos ha indicado que la investigación tiene una fiabilidad de casi el $100 \%$.

\section{Análisis estadísticos}

El análisis estadístico de esta investigación es correlacionar. Este tipo de diseño tiene como propósito medir la relación existente entre la interiorización de los falsos mitos del amor romántico, y el prejuicio sutil de carácter sexista que propicia relaciones de pareja con desequilibrio de poder entre el hombre y la mujer y los posibles episodios de violencia de género entre relaciones de jóvenes. Las variables implicadas en el estudio, han sido como variable dependiente el sexo y la edad y como variable independiente los participantes, ya que la escala se ha difundido por las redes sociales. 


\section{Resultados}

A continuación se muestran los resultados más representativos obtenidos de los cuestionarios. Adjuntando la representación gráfica de los resultados obtenidos en la encuesta (figura A1).

- Respecto al mito de la media naranja, el $65 \%$ están de acuerdo o completamente de acuerdo.

- El amor es ciego solo están en desacuerdo o completamente en desacuerdo el $29,4 \%$ del total de los participantes.

- Solo el $13,7 \%$ de los participantes creen que se puede llegar a ser feliz sin tener una relación.

- El $49,7 \%$ del total de los participantes opinan que los celos no son una muestra de amor.

- Un 5\% de los participantes considera que se puede maltratar a alguien a quien amas y casi un $11 \%$ que se puede amar a alguien a que se maltrata.

- El $73,2 \%$ del total de los participantes opinan que el amor lo puede todo.

A continuación adjuntamos los gráficos de los ítems más representativos diferenciados entre hombres y mujeres.

Figura 1.
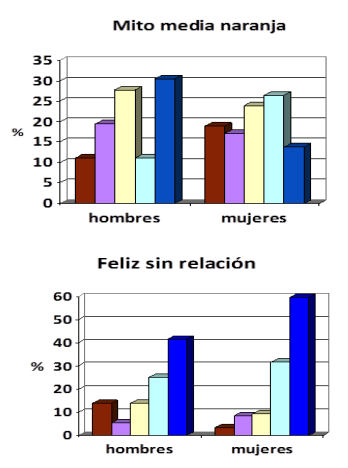

Se puede amar a quien te maltrata

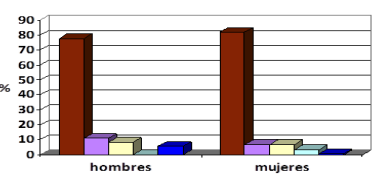

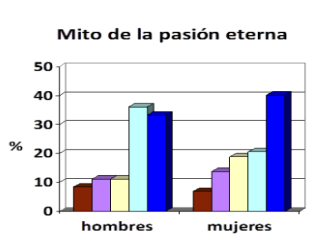

Mito del amor es ciego

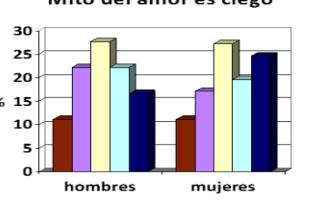

Se puede maltratar a quien se am

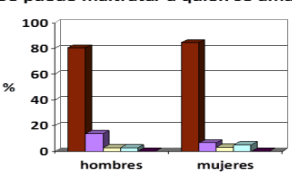

Mito del matromonio como tumba del amor

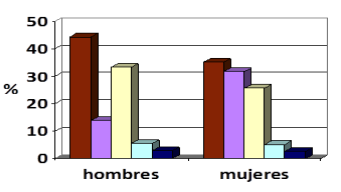

Mito de celos por amor

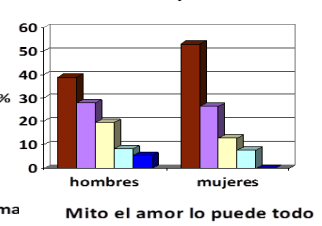

$\square$ completamente desacuerdo

$\square$ en desacuerdo

$\square$ neutro

$\square$ de acuerdo

- completamente de acuerdo

\section{Discusión}

Para finalizar, analizaremos los resultados que destacamos como más y la diferenciación de los distintos ítems entre hombres y mujeres.

De los resultados obtenidos se concluye que las mujeres tienen más interiorizado el mito de la media naranja, sintiendo que solo hay un hombre destinados para ellas.

Mientras que los hombres creen en mayor medida que no pueden ser feliz sin tener una relación, las mujeres en su gran mayoría creen que pueden ser felices sin tener una relación de pareja. 
Aunque en la mayoría creen que los celos no son una muestra de amor, los hombres dan un mayor porcentaje de aceptación a que los celos son una prueba de amor.

Por último aunque la inmensa mayoría rechazan que se puede amar a alguien a quien se maltrata o que se puede maltratar a alguien a quien se ama, una gran mayoría de los encuestados (tanto hombres como mujeres) creen que se debería dar todo por amor y que el amor lo puede todo.

\section{Conclusión}

Una vez analizados los datos concluimos que aunque los ítems más directos como "si se puede amar a alguien que te maltrata", "se puede maltratar a alguien a quien se ama" y "los celos son una prueba de amor", la gente está concienciada de que son indicadores de una relación de pareja dañinas, otros ítems más sutiles, como que "el amor lo puede todo", "el mito de la media naranja" o " el amor es ciego" la gran mayoría de los encuestados, sensiblemente más en las mujeres, hay una gran interiorización, lo que puede producir que no sean conscientes de los primeros indicadores de que se encuentran en una relación con violencia de género.

Lo que conlleva el peligro de que muchas mujeres no detecten las primeras señales, de maltrato y puedan acabar estando sometidas a manos del maltratador, padeciendo el síndrome de la mujer maltrata y haciéndoles mucho más difícil salir de una relación dañina.

Por eso concluimos que concienciar sobre todos estos mitos y los peligros que ello conlleva pueden sensibilizar a la sociedad para detectar estos primeros síntomas, pudiendo evitar que las mujeres sean víctimas de violencia de género o evitando que esa relación dure tanto como para causar estrés post traumático a la víctima

\section{Bibliografía}

Bosch, E., Ferrer, M., García, E., Ramis, M. C., Mas, M. C., Navarro, C., \& Torrens, G. (2007). Del mito del amor romántico a la violencia contra las mujeres en la pareja. Madrid: Instituto de La Mujer, Ministerio de Igualdad.

Bosch Fiol, E., Ferrer Pérez V. A., Navarro Guzmán C., \& Ferreiro Basurto, V., (2011). Profundizando en el análisis del mito del amor romántico y sus relaciones con la violencia contra las mujeres en la pareja: análisis cualitativo. Islas Baleares: Universidad de Baleares.

De la Peña, E., Ramos, E., Luzón, JM., \& Recio, P. (2011). Proyecto de Investigación sobre Sexismo y Violencia de Género en la Juventud Andaluza. España: Instituto de La Mujer, Ministerio de Igualdad.

Ferrer, V. A., Bosch, E., \& Navarro, C. (2010). Los mitos románticos en España. Boletín de psicología, 99, 7-31.

Valledor Ruitiña C., (2012) Factores de riesgo a nivel macrosistémico para la violencia de género: el papel de los mitos del amor en las relaciones de noviazgo. Oviedo: Universidad de Oviedo. 